\title{
ALTERAÇÃO NA RUGOSIDADE DO ESMALTE - EFEITO DA HIPEREXPOSIÇÃO AOS AGENTES CLAREADORES
}

\section{ARTIGO ORIGINAL}

COSTA, Samara de Oliveira ${ }^{1}$

DIAS, Angela Alexandre Meira ${ }^{2}$

COSTA, Samara de Oliveira. DIAS, Angela Alexandre Meira. Alteração na rugosidade do esmalte - Efeito da hiperexposição aos agentes clareadores. Revista Científica Multidisciplinar Núcleo do Conhecimento. Ano 05, Ed. 05, Vol. 12, pp. 47-62. Maio de 2020. ISSN: 2448-0959, Link de acesso: https://www.nucleodoconhecimento.com.br/odontologia/rugosidade-doesmalte

\section{RESUMO}

Objetivo: Avaliar a alteração na rugosidade superficial do esmalte dental bovino após o uso regular e excessivo de peróxido de carbamida a 10\% e peróxido de hidrogênio a $35 \%$. Materiais e métodos: Foram utilizados 10 blocos de esmalte do terço médio vestibular de incisivos bovinos, mantidos em solução de timol a $0,1 \%, \mathrm{pH} 7$, apresentando as dimensões de $4 \times 4 \times 2 \mathrm{~mm}$, foram obtidos por meio do uso de discos diamantados dupla face. Os blocos foram polidos com lixas d'água com granulação decrescente sequenciada de 600 a 1200, sob refrigeração a água e depois com discos de lixa sof-lex. Os 14 blocos de esmalte foram divididos em 5 grupos $(n=2)$, receberam

${ }^{1}$ Especialista em Dentística pela São Leopoldo Mandic. Graduada em Odontologia pela Universidade Veiga de Almeida.

2 Doutorado em Odontologia. Mestrado em Odontologia. Especialização em andamento em Mídias e Tecnologias em Educação. Especialização em Dentística Restauradora. Aperfeiçoamento em Correções Dento Maxilares. Graduação em Odontologia. 
tratamento superficial com Peróxido de Carbamida 10\% e Peróxido de Hidrogênio 35\%. Resultados: Os dados foram tabulados e os testes ANOVA e Tukey HSD $(\mathrm{p}<0,05)$ foram aplicados. No presente estudo não foram observadas diferenças significativas estatisticamente na rugosidade superficial do esmalte em função dos diferentes tratamentos propostos, com exceção do grupo 1 (controle). Conclusão: Pode-se concluir que não foi observada alteração na rugosidade superficial do esmalte dental bovino após o uso regular e excessivo de peróxido de carbamida a $10 \%$ e peróxido de hidrogênio a $35 \%$.

Palavras-chave: Clareamento dental, peróxido de hidrogênio, peróxido de carbamida.

\section{INTRODUÇÃO}

A procura pelo clareamento dental tem sido cada vez mais comum nos consultórios odontológicos devido ao resultado estético que ele pode proporcionar. ${ }^{1}$

Atualmente, o clareamento dental é parte integrante do tratamento restaurador, apresentando como vantagem ser uma técnica simples, conservadora e com resultados comprovados, quando realizado e indicado corretamente, pois a preservação da estrutura dental sadia deve ser o objetivo principal. ${ }^{2}$

O emprego da técnica de clareamento caseiro em dentes vitais com moldeira individual popularizou-se a partir de 1989 com a publicação do trabalho de Haywood e Heymann. ${ }^{3,4,5}$ Desde então, houve um aumento considerável das alternativas de tipos e de concentrações de agentes clareadores disponíveis no mercado. ${ }^{4}$

O branqueamento dental está diretamente relacionado à estrutura dental e permeabilidade. O esmalte se comporta como uma membrana semipermeável que é possível transmitir água e outras substâncias com pequeno peso molecular, como os íons oxigênio $\left(\mathrm{O}^{-}\right)$presente no Peróxido de Hidrogênio. Essa característica permite a difusão do oxigênio sobre a estrutura orgânica do dente e permite a reação nas moléculas manchadas promovendo o clareamento. ${ }^{3}$ 
O clareamento dental pode ser realizado de duas maneiras: no consultório ou em casa. A técnica caseira consiste no uso de géis de baixas concentrações, peróxido de hidrogênio e peróxido de carbamida, sendo mais comumente utilizado o peróxido de carbamida de $10 \%$ a $17 \%$, conjugado ao uso de uma moldeira plástica transparente confeccionada pelo dentista, o que possibilita a aplicação do agente clareador pelo paciente em casa, sempre com a supervisão do profissional. Já na técnica realizada no consultório é empregado mais comumente o peróxido de hidrogênio a 35\%. Um excelente resultado pode ser obtido ao associarmos as duas técnicas. ${ }^{4}$

A descoloração dentária pode variar em etiologia, aparência, localização, severidade e aderência a estrutura dentária, e podem ser categorizadas em intrínsecas e extrínsecas. Contudo a descoloração extrínseca pode ser removida com o procedimento de profilaxia, coloração intrínseca necessita de clareamento químico. $\mathrm{O}$ clareamento tem sido aceito como o método menos agressivo para o tratamento da descoloração dentária. ${ }^{3}$

Apesar do longo e difundido uso do clareamento exógeno como um procedimento clínico, pouco é entendido sobre sua interação com os tecidos duros e moles da cavidade bucal e as possíveis consequências destas reações a longo prazo. ${ }^{1}$

O estudo das consequências do uso excessivo desses produtos é de extrema importância, pois a obsessão por dentes cada vez mais claros tem sido frequente, sendo comum a crença de que o clareamento dos dentes é proporcional ao tempo de utilização dos agentes clareadores. Esta questão é mais séria no grupo formado por estudantes iniciantes do Curso de Odontologia, que têm fácil acesso aos agentes clareadores, mas poucos conhecem sobre os riscos de seu uso indiscriminado.

A partir desta análise, o objetivo desse estudo será avaliar a alteração na rugosidade superficial do esmalte dental bovino após o uso regular e excessivo de peróxido de carbamida a $10 \%$ e peróxido de hidrogênio a $35 \%$. 


\section{MATERIAL E MÉTODOS}

\subsection{LISTA DE MATERIAIS}

1. Dentes bovinos;

2. Solução de timol a $0,1 \%, \mathrm{pH} 7$;

3. Discos diamantados dupla face (KG Sorensen, Barueri, São Paulo, Brasil) ;

4. Lixas d'água com granulação decrescente seqüenciada de 600 a 1200;

5. Espátula ํo 1 (Millennium);

6. Pinça para algodão (Millennium);

7. Fotopolimerizador (kavo);

8. Saliva artificial- Farmácia UFRJ;

9. 4 recipientes plásticos pretos com tampa;

10. Discos de lixa de óxido de alumínio com granulação decrescente (Sof-Lex®/3M ESPE, Sumaré, SP, Brasil);

11. Caneta de baixa rotação (Kavo);

12. Micromotor, peça de mão e contra-ângulo (Kavo);

13. Peróxido de Carbamida $10 \%$ (whitnessperfect)

14. Peróxido de Hidrogênio 35\% (Whitness HP);

15. Rugosímetro modelo SJ-201P (Mitutoyo Sul Americana)

16. Resina de poliestireno

17. Cera utility

18. Máquina fotográfica digital (Samsung SII).

\subsection{METODOLOGIA}

\subsubsection{OBTENÇÃO DOS BLOCOS DE ESMALTE}

Dez blocos de esmalte do terço médio vestibular de incisivos bovinos, mantidos em solução de timol a $0,1 \%, \mathrm{pH} 7$, apresentando as dimensões de $4 \times 4 \times 2 \mathrm{~mm}$ foram obtidos por meio do uso de discos diamantados dupla face. 
Figura 1: A- Terço médio do incisivo bovino ; B- Disco diamantado dupla face; C-Área de corte por vestibular; D- Área de corte por incisal.

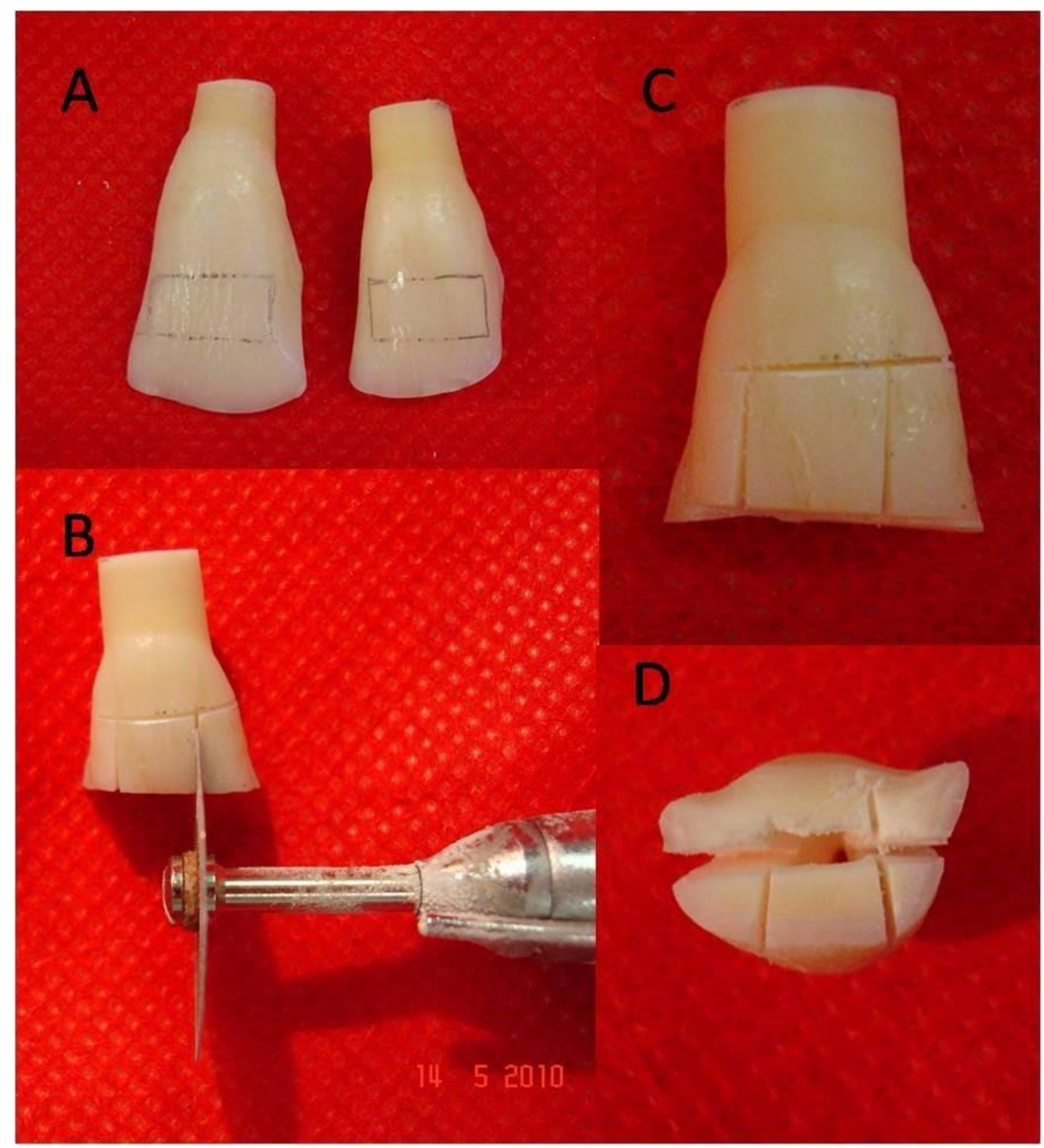

Fonte: Elaboração da autora (2019) 


\subsubsection{OBTENÇÃO DOS CORPOS DE PROVA}

Os fragmentos de esmalte foram posicionados sobre uma tira de cera utility. Foram utilizados como molde pedaços de cano de PVC que foram preenchidos com resina de poliestireno. Os blocos foram polidos com lixas d'água com granulação decrescente sequenciada de 600 a 1200, sob refrigeração a água e depois com discos de lixa sof-lex.

\subsubsection{ENSAIO DE RUGOSIDADE SUPERFICIAL E SELEÇÃO DOS BLOCOS DE ESMALTE}

Os 14 blocos de esmalte foram divididos em 5 grupos $(n=2)$, cujo tratamento superficial está descrito na tabela 1.

Tabela 1: Tratamento superficial dos grupos testados

\begin{tabular}{|c|c|c|c|}
\hline GRUPO & TRATAMENTO & PRODUTO & TRATAMENTO \\
\hline $\begin{array}{l}\text { G1 } \\
\text { Grupo } \\
\text { controle }\end{array}$ & Sem tratamento & Saliva artificial & Não clareado \\
\hline $\begin{array}{l}G \quad 2 \\
\text { Clareador } \\
\text { caseiro }\end{array}$ & $\begin{array}{l}\text { Peróxido de } \\
\text { carbamida } 10 \%\end{array}$ & $\begin{array}{l}\text { WhitnessPerfect } \\
10 \%\end{array}$ & 6 horas por dia/ 15 dias \\
\hline $\begin{array}{l}\text { G } 3 \\
\text { Clareador } \\
\text { caseiro }\end{array}$ & $\begin{array}{l}\text { Peróxido de } \\
\text { carbamida } 10 \% \\
\text { superexposto }\end{array}$ & $\begin{array}{l}\text { WhitnessPerfect } \\
10 \%\end{array}$ & 6 horas por dia/ 30 dias \\
\hline $\begin{array}{l}\text { G } 4 \\
\text { Clareador } \\
\text { Profissional }\end{array}$ & $\begin{array}{l}\text { Peróxido de } \\
\text { Hidrogênio a } 35 \%\end{array}$ & Whitness HP35\% & $\begin{array}{l}3 \text { aplicações de } 15 \\
\text { minutos/ fotoativação por } \\
30 \text { segs./ por semana/ } 2 \\
\text { semanas }\end{array}$ \\
\hline
\end{tabular}




\begin{tabular}{ll|l|l}
\hline $\begin{array}{l}\text { G de de } \\
\text { Clareador } \\
\text { Profissional }\end{array}$ & $\begin{array}{l}\text { Peróxido Whitness HP35\% } \\
\text { Hidrogênio a 35\% }\end{array}$ & $\begin{array}{l}3 \text { aplicações de } 5 \text { minutos/ } \\
\text { fotoativação por } 30 \text { segs./ } \\
\text { superexposto }\end{array}$ & por semana/4 semanas
\end{tabular}

Fonte: Elaboração da autora (2019)

O ensaio de rugosidade superficial inicial foi executado com o auxílio do rugosímetro modelo SJ-201P (Mitutoyo Sul Americana), cuja ponta apalpadora de tamanho de $0,005 \mathrm{~mm}$ de raio, se deslocou a uma velocidade de $1 \mathrm{~mm} / \mathrm{seg}$. Foram realizadas 5 leituras em esmalte em cada corpo-de-prova.

Após o clareamento, nova análise de rugosidade foi feita, seguindo os mesmos parâmetros.

A partir dos dados obtidos, foi calculada a alteração na rugosidade superficial dos mesmos. Esta foi comparada através da análise de variância e teste de Tukey. 
Figura 2: A- Aplicação de 3 gotas de peróxido de hidrogênio concentrado; B- Aplicação de 1 gota de espessante; C- Resultado da mistura dos produtos; D- Aplicação do clareador nos fragmentos de dente bovino; E- Fotopolimerização por 30 segundos.

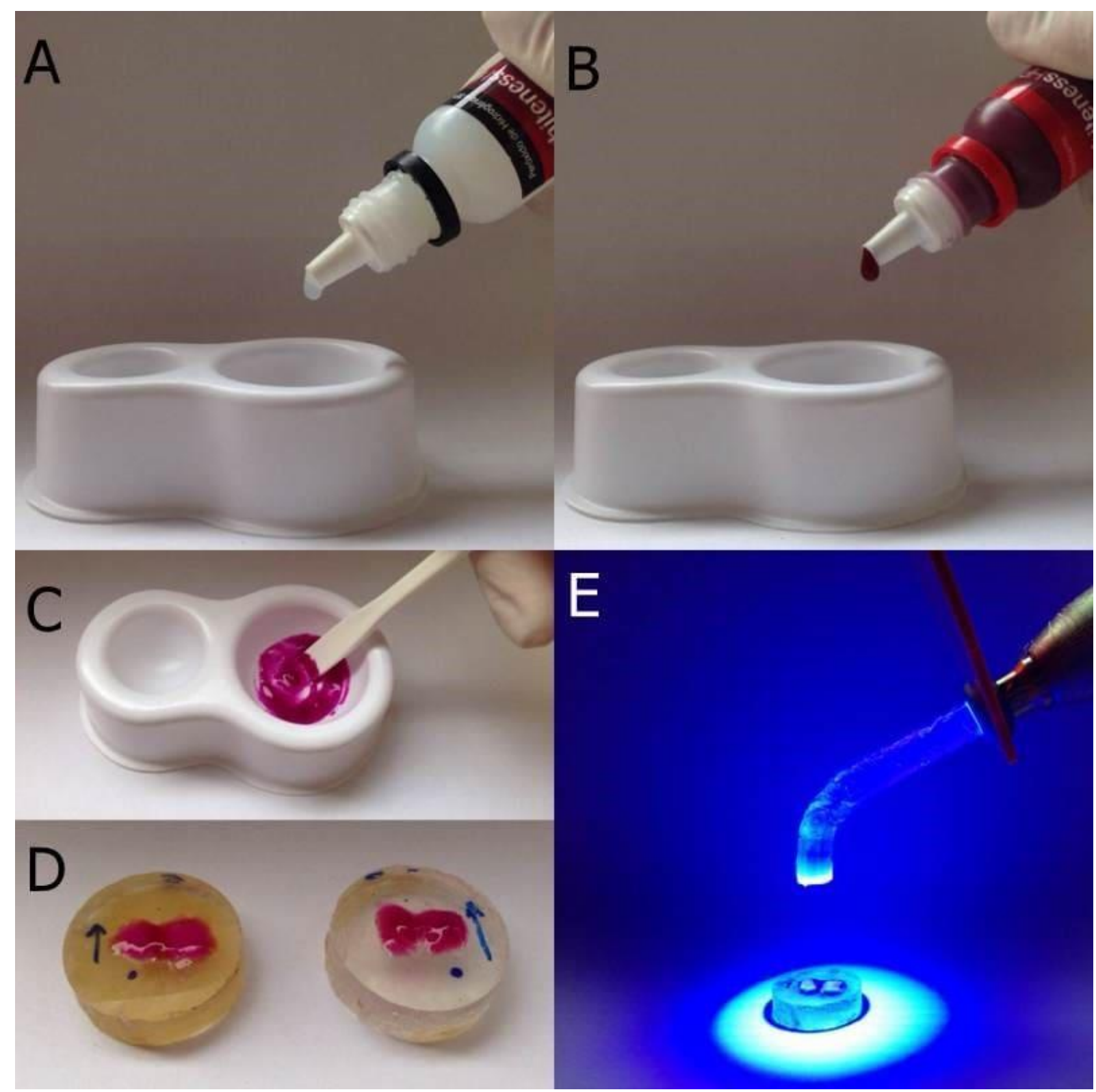

Fonte: Elaboração da autora (2019) 
Figura 3: Aplicação do gel clareador caseiro.

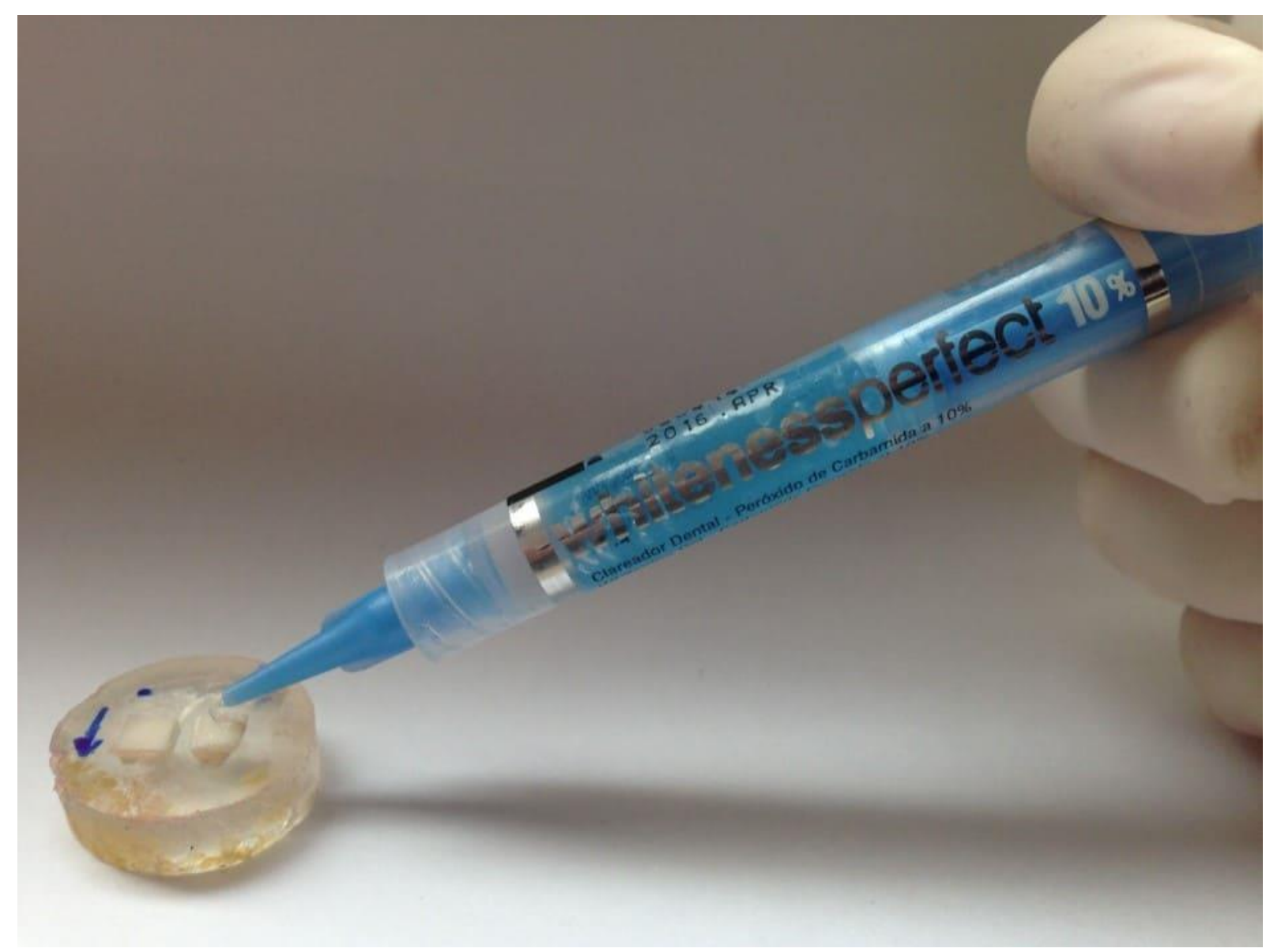

Fonte: Elaboração da autora (2019) 


\section{RESULTADOS}

Os dados foram tabulados e os testes ANOVA e Tukey HSD $(p<0,05)$ foram aplicados.

Tabela 1.

Anova: fator único

\begin{tabular}{|c|c|c|c|c|}
\hline Grupo & Contagem & Soma & Média & Variância \\
\hline \multirow{2}{*}{ SALIVA } & 5 & 11,2 & 2,24 & 1,703 \\
\hline & 5 & 17,4 & 3,48 & 1,532 \\
\hline \multirow[t]{2}{*}{ Peróxido 10\% } & 5 & 6,8 & 1,36 & 0,248 \\
\hline & 5 & 6,6 & 1,32 & 0,117 \\
\hline \multirow[t]{2}{*}{ Peróxido $10 \% \uparrow$} & 5 & 7,2 & 1,44 & 0,063 \\
\hline & 5 & 5,9 & 1,18 & 0,052 \\
\hline \multirow[t]{2}{*}{ Peróxido 35\% } & 5 & 6,5 & 1,3 & 0,335 \\
\hline & 5 & 6,4 & 1,28 & 0,597 \\
\hline \multirow[t]{2}{*}{ Peróxido $35 \% \uparrow$} & 5 & 5,9 & 1,18 & 0,482 \\
\hline & 5 & 6,4 & 1,28 & 0,072 \\
\hline
\end{tabular}

ANOVA

\begin{tabular}{|c|c|c|c|c|c|c|}
\hline Fonte da variação & $S Q$ & gl & $M Q$ & $F$ & valor- $P$ & Fcrítico \\
\hline Entre grupos & 23,7642 & 9 & 2,640467 & 5,076844 & 0,000138 & 2,124029 \\
\hline Dentro dos grupos & 20,804 & 40 & 0,5201 & & & \\
\hline Total & 44,5682 & 49 & & & & \\
\hline
\end{tabular}

Fonte: Elaboração da autora (2019)

Como $p<0,05$, sabe-se que houve diferença estatística na rugosidade superficial do esmalte entre os grupos. O teste Tukey HSD, figura 4, foi utilizado para determinar que grupos da amostra apresentaram esta diferença. De acordo com esta análise, não foram observadas diferenças significativas na rugosidade superficial do esmalte em 
função dos diferentes tratamentos clareadores propostos, com exceção do grupo 1 (controle).

Figura 4: Tukey HSD- Diferença estatisticamente significante na rugosidade superficial do esmalte do grupo controle (Saliva).

\begin{tabular}{|c|c|c|c|c|}
\hline \multirow[b]{2}{*}{ Cell No. } & \multicolumn{4}{|c|}{$\begin{array}{l}\text { Tukey HSD test; variable RUGOSIDADE (LFS2, } \\
\text { Homogenous Groups, alpha }=, 05000 \\
\text { Error: Between MS }=, 89778, \mathrm{df}=90,000\end{array}$} \\
\hline & Tratamento & $\begin{array}{c}\text { RUGOSIDADE } \\
\text { Mean }\end{array}$ & 1 & 2 \\
\hline 2 & $10 \%$ & 0.750000 & 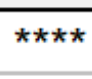 & \\
\hline 4 & $35 \%$ & 1.050000 & $\star * \star \star *$ & \\
\hline 5 & $35 \%+$ & 1.200000 & $\star \star \star \star *$ & \\
\hline 3 & $10 \%+$ & 1.250000 & $\star \star \star \star *$ & \\
\hline 1 & SALIVA & 2.650000 & & **** \\
\hline
\end{tabular}

Fonte: Elaboração da autora (2019)

Gráfico 1: Gráfico representativo da alteração na rugosidade média superficial do esmalte em função dos diferentes tratamentos propostos.

\section{Rugosidade média - $\mu \mathrm{m}$}

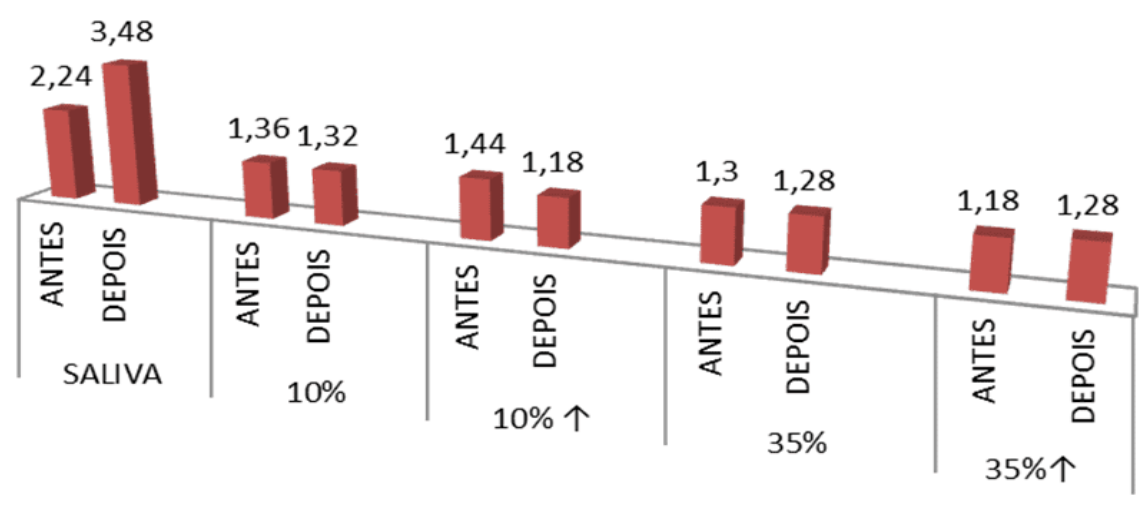

Fonte: Elaboração da autora (2019) 


\section{DISCUSSÃO}

Para este estudo foram selecionados incisivos bovinos devido à semelhança estrutural e histológica destes com os dentes humanos, por serem de fácil coleta, conseguidos em grandes quantidades e possuírem volume vestibular suficiente, onde se consegue uma área plana extensa para o propósito do estudo. ${ }^{6,7}$

O esmalte bovino ainda apresenta homogeneidade, mostrando-se algumas vezes como uma variabilidade biológica menor que a do esmalte humano, uma vez que não estão expostos às altas concentrações de flúor e não sofrem desafios cariogênicos. ${ }^{6,7}$

O estudo do clareamento dental tem sido alvo de muitas pesquisas realizadas atualmente, direcionadas aos seus efeitos clínicos, possíveis efeitos colaterais, entre outros assuntos. ${ }^{8}$ Isto porque o uso dos peróxidos para restauração da cor natural ou para obtenção de uma cor mais clara em dentes escurecidos ou manchados é encarado como um meio mais conservador para a devolução de uma estética mais agradável disponível no presente. 8,9

A questão das alterações morfológicas da superfície do esmalte após o clareamento é controversa, apesar do fato de que um grande número de estudos vem investigando a possível formação e e manutenção dessas alterações. No entanto, a maioria dos estudos morfológicos que foram realizados in vitro, levaram a resultados diversos, que podem estar relacionados às diferentes condições de ensaios, aos aspectos morfológicos e as propriedades mecânicas estudadas. ${ }^{10}$

A proposta do emprego de ativação por equipamentos de energia eletromagnética (luz) baseia-se na vantagem de que fontes de luz aceleram a decomposição e formam uma maior quantidade de radicais livres. ${ }^{1,2,3}$

Como mencionado anteriormente, os dados referentes às alterações morfológicas na estrutura do esmalte são conflitantes, em função da enorme variedade de métodos utilizados nos estudos, bem como a influência da diversidade de produtos, 
concentrações, $\mathrm{pH}$, métodos de avaliação das alterações, tempos de ação dos géis, orientações técnicas e marcas comerciais analisadas. ${ }^{6}$

No presente estudo não foram observadas diferenças significativas estatisticamente na rugosidade superficial do esmalte em função dos diferentes tratamentos propostos, com exceção do grupo 1 (controle).

A simples imersão na saliva artificial foi capaz de alterar de modo significativo a rugosidade superficial do esmalte dentário no grupo controle. Este comportamento no esmalte pode justificar-se pelo fato da solução de saliva artificial não ter sido trocada diariamente, como acontece na maioria dos estudos e, de acordo com o comentário de Pimenta LA, pode haver um decréscimo no pH da solução nesta condição, o que poderia levar a perda mineral do substrato e consequentemente ao aumento em sua rugosidade. ${ }^{9}$

A partir da análise do gráfico 1, gerado a partir das leituras feitas pelo rugosímetro Mitutoyo, nos grupos que receberam tratamento clareador, percebe-se que houve uma discreta diminuição na rugosidade superficial, com exceção do grupo hiperexposto ao peróxido de hidrogênio a 35\%. Este resultado se assemelha ao do estudo realizado por Faraoni-Romano J, Silveira A, Turssi $C$ et $a^{9}{ }^{9}$, no qual foi observada a diminuição dos valores da rugosidade no esmalte.

A concentração de peróxido de hidrogênio é um fator relevante para obtenção dos resultados de valores de rugosidade significantemente maiores, tal aumento ocorre em razão da redução da quantidade de cálcio e fósforo no esmalte, após clareamento dental. ${ }^{2}$

Não foram observadas diferenças significativas na rugosidade do esmalte com o uso de Peróxido de Carbamida a 10\% tanto no grupo que foi exposto de forma regular quanto no grupo que foi superexposto, confrontando-se com o estudo de Daniel C, Soares $D$, Andreeta $M$ et al $^{1}$ em que uma diferença estatística foi observada no esmalte dentário tratado com peróxido de carbamida a 10\%, com aumento significante da rugosidade quando esse agente clareador foi aplicado. 
Estudos anteriores indicaram que o Peróxido de Hidrogênio 30-35\% causa alteração superficial, por ser um forte agente oxidante, por isso seu uso está indicado apenas por profissionais. Indicaram também algumas áreas da superfície do esmalte que não apresentaram alterações. Entretanto, desmineralização e falta de suavidade provavelmente resultaram no aumento da média da rugosidade superficial. ${ }^{11}$ Porém, assim como no presente estudo, trabalhos como o de Daniel C, Soares D, Andreeta $M$ et al ${ }^{1}$ não foram observadas alterações significantes da rugosidade superficial do esmalte após clareamento com Peróxido de Hidrogênio 38\%, associado ou não a luz LED.

O trabalho realizado por Cardoso $R$, Oda $M$, Junior $A E T A L^{2}$ revelou resultados diferentes quanto à utilização de Peróxido de Hidrogênio 35\% com e sem fotoativação. A rugosidade superficial do esmalte não foi alterada após ser submetido a tratamento clareador sem fotoativação, porém mostrou haver alteração após o clareamento ser realizado com um fotoativador.

O que motivou a execução deste trabalho foi o fato de que um aumento da rugosidade superficial do esmalte, decorrente da exposição a agentes clareadores, poderia facilitar a adesão de microrganismos na superfície dental, ${ }^{12}$ assim como causar um maior acúmulo de biofilme ${ }^{2}$. Além disto, uma superfície rugosa poderia afetar o desgaste de dentes e de materiais restauradores, aumentando a suscetibilidade ao manchamento. Sendo assim, é importante estudar a rugosidade do esmalte após procedimentos que tem potencial de causar erosão nos tecidos dentais. ${ }^{2.13}$

\section{CONCLUSÃO}

1. Considerando as limitações do estudo in vitro, pode-se concluir que não foi observada alteração na rugosidade superficial do esmalte dental bovino após o uso regular e excessivo de peróxido de carbamida a $10 \%$ e peróxido de hidrogênio a $35 \%$.

2. O aumento da rugosidade superficial do esmalte pode afetar o desgaste dos dentes, aumentar a suscetibilidade ao manchamento e pode resultar também em um maior acúmulo de biofilme. 


\section{REFERÊNCIAS}

1. Daniel CP, Soares DGS, Andreeta MMRB, Hernandes AC, Hebling J, Costa CAS. Efeitos de diferentes sistemas de clareamento dental sobre a rugosidade e morfologia superficial do esmalte e de uma resina composta restauradora. Odontol Bras Central. 2011;20(52).

2. Cardoso RM, Oda M, Junior ACCA, Freitas LM, Sampaio HR, Vasconcellos BT. A rugosidade do esmalte dental e o tratamento clareador. Revista Pós-Graduação. 2012;19(2):39-45.

3. Mondelli RFL, Azevedo JFDG, Francisconi AC, Almeid CM, Ishikiriama SK. Comparative clinical study of the effectiveness of different dental bleaching methods - two year follow-up. Journal of Applied Oral Science. 2012;20(4):435-43.

4. Conceição EN. Dentística: Saúde e Estética. $2^{\mathrm{a}}$ ed. Porto Alegre: Artmed, 2007, p. 235.

5. Mendes APKF, Barceleiro MO, dos Reis RSA, Bonato LL, Dias KRHC. Changes in surface roughness and color stability of two composites caused by different bleaching agents. Brazilian Dental Journal. 2012;23(6):659-666.

6. Trentino $A C$, Estudo in vitro da variação do $\mathrm{pH}$ de agentes clareadores e seu efeito sobre o desgaste e rugosidade superficial do esmalte bovino após escovação simulada. Tese de Mestrado, Bauru: Universidade de São Paulo, 2011.

7. de Azevedo JFDG, Avaliação do desgaste e da rugosidade superficial do esmalte bovino submetido ao clareamento e escovação simulada. Tese de Mestrado, Bauru: Universidade de São Paulo, 2005.

8. Riehl $\mathrm{H}$, Estudo in vitro do efeito de três diferentes agentes clareadores sobre a dureza e rugosidade do esmalte dentário bovino. Tese de Doutorado, Bauru: Universidade de São Paulo, 2002.

9. Faraoni-Romano JJ, da Silveira AG, Turssi CP, Serra MC. Bleaching agents with varying concentrations of carbamide and/or Hydrogen 
Peroxides: Effect on dental microhardness and roughness. Journal of Esthetic and Restorative Dentistry. 2008 Dec; 20(6):395-404.

10. Cadenaro M, Breschi L, Nucci C, Antoniolli F, Visintini E, Prati C, Matis BA, Di Lenarda R. Operative Dentistry. 2008Mar-Apr;33(2):127-34.

11. Pinto CF, de Oliveira R, Cavalli V, Giannini M. Peroxide bleaching agent effects on enamel surface microhardness, roughness and morphology. Brazilian Oral Research. 2004 Dec;18(4):306-11.

12. Daniel CP. Avaliação dos efeitos causados por diferentes sistemas de clareamento dental sobre a estrutura superficial do esmalte e resina composta restauradora. Tese de Mestrado, Araraquara: Universidade Estadual Paulista, 2011.

13. da Cunha LA. Avaliação da rugosidade superficial e da alteração de cor do esmalte humano submetido ao clareamento dental e/ou refrigerante a base de cola, em função da escovação simulada. Tese de Doutorado, São José dos Campos: Universidade Estadual Paulista, 2008.

\section{APÊNDICES}

Leituras da rugosidade superficial, por grupo:

\begin{tabular}{|c|c|}
\hline \multicolumn{2}{|c|}{ GRUPO 1} \\
\hline \multicolumn{2}{|c|}{ SALIVA } \\
\hline 1,2 & 2,6 \\
\hline 1,5 & 5,6 \\
\hline 1,2 & 3,2 \\
\hline 3,4 & 2,6 \\
\hline 3,9 & 3,4 \\
\hline
\end{tabular}

Fonte: Elaboração da autora (2019)

\section{GRUPO 2}

$10 \%$ 


\begin{tabular}{|l|l|}
\hline $\mathbf{1 , 1}$ & 1,8 \\
\hline $\mathbf{1}$ & 1,5 \\
\hline $\mathbf{1 , 9}$ & 1 \\
\hline $\mathbf{1 , 9}$ & 1,3 \\
\hline $\mathbf{0 , 9}$ & 1 \\
\hline
\end{tabular}

Fonte: Elaboração da autora (2019)

\begin{tabular}{l}
\begin{tabular}{|l|l|}
\hline GRUPO 3 \\
\hline $\mathbf{1 0 \%} \uparrow$ \\
\hline $\mathbf{1 , 4}$ & 1,1 \\
\hline $\mathbf{1 , 5}$ & 0,9 \\
\hline $\mathbf{1 , 4}$ & 1,1 \\
\hline $\mathbf{1 , 1}$ & 1,3 \\
\hline $\mathbf{1 , 8}$ & 1,5 \\
\hline
\end{tabular} \\
\hline
\end{tabular}

Fonte: Elaboração da autora (2019)

\begin{tabular}{|l|l|}
\hline \multicolumn{2}{|l|}{ GRUPO $\mathbf{4}$} \\
\hline $\mathbf{3 5 \%}$ \\
\hline $\mathbf{1}$ & 2,6 \\
\hline $\mathbf{2 , 2}$ & 0,6 \\
\hline $\mathbf{1 , 1}$ & 0,9 \\
\hline $\mathbf{0 , 7}$ & 1,2 \\
\hline $\mathbf{1 , 5}$ & 1,1 \\
\hline
\end{tabular}

Fonte: Elaboração da autora (2019)

\begin{tabular}{|l|l|}
\hline \multicolumn{2}{|l|}{ GRUPO $\mathbf{5}$} \\
\hline $\mathbf{3 5 \%} \uparrow$ \\
\hline $\mathbf{1 , 4}$ & 1,3 \\
\hline $\mathbf{2 , 3}$ & 1 \\
\hline $\mathbf{0 , 8}$ & 1,3 \\
\hline
\end{tabular}

RC: 51158

Disponível em: https://www.nucleodoconhecimento.com.br/odontologia/rugosidade-do-esmalte 


\begin{tabular}{|l|l|}
\hline $\mathbf{0 , 8}$ & 1,1 \\
\hline $\mathbf{0 , 6}$ & 1,7
\end{tabular}

Fonte: Elaboração da autora (2019)

Enviado: Abril, 2020.

Aprovado: Maio, 2020. 